Adolescents' multi-layered media processing: A panel study on positive and negative perceptions towards ideals and adolescents' appearance anxiety

$$
\text { Jolien Trekels }{ }^{1,2} \& \text { Steven Eggermont }{ }^{1}
$$

${ }^{1}$ School for Mass Communication Research, Faculty of Social Sciences, KU Leuven, Leuven Belgium

${ }^{2}$ Research Foundation Flanders (FWO-Vlaanderen)

Keywords: Media, Peers, Viewer Agency, Adolescents, Body Image Investment

This is a preprint version of the manuscript (11.04.2021)

The manuscript has been submitted for peer review

Author note

Email addresses: Jolien.Trekels@kuleuven.be; $\underline{\text { Steven.Eggermont@kuleuven.be }}$

Correspondence concerning this article should be addressed to Jolien Trekels, School for Mass Communication Research, KU Leuven, Parkstraat 45, B-3000 Leuven, Belgium, Jolien.Trekels@kuleuven.be, Tel: +32 16323414 - Fax: +32 16320497.

Conflict of interest: The authors declare that they have no conflict of interest.

This work was supported by the Research Foundation Flanders (FWO), grant nr. 12X0820N 


\begin{abstract}
An active audience perspective on media effects suggests that viewers are not merely exposed but rather reactive to multiple - and possibly opposing - messages. Studies taking account of idealized and counter-idealized messages simultaneously are, however, lacking. Considering that diverse messages are abundantly present in appearance media, the current study aims to introduce an agentic perspective by focusing on the media-body image association. Results of a three-wave longitudinal survey among 971 early adolescents $\left(M_{\text {age }}=11.14 ; S D=1.13\right)$ show that media-focused peer interactions (W1), but not media exposure (W1), were associated with perceived benefits as well as costs for investing in appearance (W2). Polynomial regression analyses pointed out that the association between benefits and costs (i.e., interaction; W2) was curvilinearily related to body image investment (W3). The findings emphasize the variable vulnerability of adolescents to the media effect and the importance of acknowledging multilayered media messages.
\end{abstract}

Keywords: Media, Peers, Viewer Agency, Adolescents, Body Image Investment 


\section{Adolescents' multi-layered media processing: A panel study on positive and negative perceptions towards ideals and adolescents' appearance anxiety}

Research has convincingly demonstrated the high frequency with which media contain idealized representations. It documented a persistent 'glamorizing' of (aspects of) life, through a strong emphasis on and positive reinforcement of a narrow set of hard-to-reach ideals, for instance in the realm of appearance and attractiveness (e.g., Levine \& Murnen, 2009). Aligning with the theoretical expectation that idealization may permeate in (young) people's normative frames, exposure to such idealizations has been shown to harm the wellbeing of (young) audiences (e.g., Saiphoo \& Vahedi, 2019). Nowadays, however, early adolescents are also likely to come across counter- or disillusioning messages that aim to contextualize that same behavior or appearance, such as warning labels on idealized media images (Cohen et al., 2020; Rodgers et al., 2021).

The current study aims to disentangle the influence of exposure to such conflicting messages by taking an agentic perspective on media processing. We follow the assertion that media use is not a passive experience (Ward et al., 2006) and that audience activity should be taken into account (e.g., Livingstone, 1998). More specifically, we consider early adolescents' media diet as containing both idealized messages and messages that explicitly or implicitly challenge those (stereo)typical idealizations. Conflicting media exposure might, then, cognitively result in a complex interaction between the those perceived benefits and costs of the portrayed behavior or appearance. By investigating whether early adolescents weigh both the benefits and costs (i.e., balance/imbalance between benefits and costs) before cognitively integrating the media's portrayal into their self-concept, we aim to add an active component to our understanding of the media effect.

The current study will empirically test this perspective with regard to a highly pertinent aspect of adolescent self-concept: appearance and body image. Substantial pubertal (and 
related physical), cognitive, and social changes augment adolescents' awareness of and concern with their appearance. Moreover, the co-existence of literature shows that adolescents come across messages on both the positive and negative consequences of being appearance-focused (e.g., Groesz et al., 2002; Mulgrew et al., 2018; Rodgers et al., 2021). Testing the value of the agentic perspective on media processing would, therefore, be especially relevant for the link between media use and body image investment among early adolescents.

To adequately understand how early adolescents' cognitive body image investment is affected by the processing of conflicting media messages, two additional factors need to be included. First, adolescents' media-focused interactions with their peers will be considered as a context in which media messages are disseminated and interpreted. Second, specific attention will be paid to the role of age in adolescents' capability to calibrate risk and reward.

\section{Media Exposure and Cognitive Body Image Investment}

One of the possible derivatives of early adolescents' encounter with and processing of appearance-focused messages is an increased cognitive investment in their body image. Early adolescents become more skilled and motivated to engage in comparisons with fixed (e.g., mass media figures) or relative (e.g., peers) standards in order to gain a sense of who they are and their social standing (Harter, 2015). Consequently, adolescent self-concept is rooted in their relative standing towards others' expectations and norms (Harter, 2015). Mass and social media's focus on ideal appearances together with early adolescents' inclination to evaluate themselves against standards (i.e., the ideal), may encourage them to take an appearance perspective on life (Kleemans et al., 2018; Zsakai et al., 2017). As such, a substantive part of the perception of one's body image is inherently social (Gleeson \& Frith, 2006). The current study will consider social appearance anxiety as a measure of body image in order to acknowledge the complexity of the ways in which people perceive and evaluate their bodies in 
different (imagined) contexts, such as a context in which one is judged based on their appearance.

\section{An Agentic Perspective on Media Processing}

Figure 1 depicts the agentic perspective on media processing, which holds two important parts. First, the model acknowledges that early adolescents can be exposed to multiple messages from which they can infer different meanings. The second part of the model holds the agency of viewers in internalizing these different messages, with cognitive body image investment as a possible outcome.

[insert Figure 1 here]

Part 1: Media content is multi-layered. In their attempt to come to a better understanding of the media effect, researchers have focused on developing and testing theoretical models to accurately describe the association between media and well-being. One of the most often cited models is social cognitive theory (Bandura, 2001), which suggests that observing attractive role models being rewarded for their actions affects the viewers' intention to imitate those actions. This reward perspective is also observed with the literature on the media-body image association. For instance, Trekels \& Eggermont, (2017) empirically confirmed that early adolescents learn to associate benefits with an attractive appearance from their television exposure. Following content-analytical and empirical studies building on mass and social media's glorification of attractiveness (Northup \& Liebler, 2010; Tiggemann et al., 2018) to explain the media-body image association, we expect that:

Hla: Media use is positively related to early adolescents' perception of benefits for attractiveness.

At the same time, however, there are some indications in the literature that mass and social media are also able to spur thought on the importance of valuing more diverse appearance standards that move beyond the narrowly defined and unrealistic ideals (i.e., body 
positivity messages; Cohen et al., 2021; Rodgers et al., 2021). Next to the increasing occurrence of body positive messages, several initiatives have been set up - and proven to be partially effective - in schools to teach adolescents how to critically analyze and interpret the content they are exposed to (e.g., Zuair \& Sopory, 2020). A study by Burnette and colleages (2017) showed that girls in $7^{\text {th }}$ and $8^{\text {th }}$ grade already displayed high media literacy, appreciation of diversity, and confidence. Such findings add to our suggestion that we should recognize the complexity of the process and not overestimate the vulnerability of early adolescents to the media effect. Relatedly, Daniels and Zurbriggen (2016) found that adolescent girls and women rated an overly appearance-focused profile owner on social networking sites as less physically attractive, less socially attractive, and less competent to complete tasks than a non-sexualized profile owner. Adolescent girls and women thus seem to be critical of appearance-focused others, implying that appearance-related issues are not merely presented in a rewarding context nor that adolescents would interpret attractiveness solely as rewarding. As such, from their media use, adolescents could deduct that an appearance focus can come with certain costs, as well. Therefore, we expect that:

H1b: Media use is positively related to early adolescents' perception of costs for attractiveness.

Considering the above, it seems warranted to acknowledge a level of agency with which individuals navigate through this multitude of messages about (the consequences of) being appearance-focused. In fact, whereas the agency of the individual in the selection of media messages has been studied in past research, for instance, through adopting a uses and gratifications (Rubin, 1994) and selective exposure perspective (Zillmann \& Bryant, 1985), the agency of individuals in the processing of media messages has received less attention.

Studies on the media selection hypothesis draw on insights from both selective exposure theory (Zillmann \& Bryant, 1985) and cognitive dissonance theory (Festinger, 1962) and have 
shown that individuals selectively avoid or expose themselves to certain content (KnoblochWesterwick, 2014; Smith et al., 2008). These studies fit in a line of research that sees the audience as active (Morley, 1993), but only considers this active role in choosing the content one is exposed to. One of the most important demurrals to this line of thought is that it seems inaccurate to assume that there are no structural influences at play in this process. Specifically, the question raises whether the individual has active control over the structure of the information process (Biocca, 1988) as certain content - such as advertising, content on one's SNS feed, or peers' opinions about media content expressed during conversations - can be forced onto an individual. As such, it is argued that the individual is best described not as passive or active but reactive to the structure and content of the media (Biocca, 1988; Livingstone, 1998). In this regard, it seems necessary for communication theories to allow for an agentic perspective on how viewers navigate through different and conflicting messages. Notably, it can be argued that the agency of the media audience may lie primarily in the processing and evaluation of the content they are exposed to (i.e., the second part of the agentic model on media processing) rather than in their choice for media content alone. An important caveat that accompanies this stipulation is that we do not assume that youth will always actively and/or consciously processes media content but rather that the agency of the individual lies within the internalization of certain types of media messages.

\section{Part 2: Balance/Imbalance Between Benefits and Costs for Attractiveness. Next to} the perceived benefits and costs for attractiveness that adolescents derive from their media exposure (part 1), we argue that the unique intertwining of these perceptions plays into the extent to which media's portrayals are cognitively integrated in one's self-concept (part 2).

Reinforcements, either negative or positive, are considered crucial in the learning and internalization of norms (Scott, 1971). Learning theories (e.g., Bandura's social cognitive theory, 1989) postulate that individuals infer normative beliefs and behavioral scripts from 
observing attractive role models being rewarded or punished for their actions. Positive (or negative) reinforcement can, when valued by the individuals, trigger (or inhibit) a modeling process. Despite the popularity of social cognitive theory (Bandura, 1989, 2001) in explaining media-effects, Nabi and Clark (2008) noticed that prior media studies did not adequately test these presumptions. In an attempt to fill this important gap in the literature, they tested whether different depictions (i.e., either positive or negative reinforcements for risky sexual behavior) would differently affect the outcome (i.e., likelihood of engaging in the depicted risky sexual behavior). They concluded that inexperienced individuals reported a higher likelihood of engaging in the behavior after viewing, regardless of the positive or negative outcomes associated with it. We believe their findings are a first indication that the observation of rewards (or punishments) alone is insufficient to explain the outcome. Although Nabi and Clark (2008) consider prior experience as the main explanation for their findings, we believe that considering both perceived negative and positive outcomes simultaneously could provide additional insights into the process. Specifically, conformity to norms is determined by intrinsic or extrinsic reinforcements, but oftentimes also entails costs (Scott, 1971). For instance, being appearance-focused can be perceived as bringing about certain positive outcomes such as popularity or happiness (Trekels \& Eggermont, 2017). At the same time, however, it can negatively impact one's friendships through jealousy or impact school when schoolwork is put aside (Nelson \& Brown, 2018). If we borrow insights from expectancy value perspectives on motivation (e.g., Wigfield \& Eccles, 2000), which contend that individuals' decisions to perform an activity will be determined by the values and costs associated with that activity, we argue that a weighing process of both the perceived benefits and the costs of investing in attractiveness (i.e., balance/imbalance between benefits and costs) occurs upon cognitively integrating media's appearance ideals into one's self-concept. To that end, we propose a typology of balance/imbalance types. First, following the traditional media-effect studies 
(Fischer et al., 2011), it can be assumed that early adolescents take away a positive imbalance (i.e., benefits outweigh costs) from their media exposure which, in turn, might increase early adolescents' investment in their body image.

H2a: A positive imbalance between benefits and costs is positively associated with cognitive body image investment.

Second, if we follow audience research (Biocca, 1988) to assume that early adolescents encounter and process both glorifying and counter-messages (e.g., Mulgrew et al., 2018), we can expect that early adolescents' media exposure might result in a balance between benefits and costs, thereby canceling each other out. We believe that observing benefits and costs for attractiveness to the same degree might actually confine the impact of mass media exposure on early adolescents' cognitive body image investment:

H2b: A balance between benefits and costs is not related to cognitive body image investment, thereby attenuating the influence of media use.

Lastly, just like the power of mass media to affect early adolescents' perception of positive consequences for attractiveness, media exposure might also result in a negative imbalance whereby a focus on the costs outweighs the perceived benefits. No study has yet investigated the possibility of a negative imbalance between benefits and costs for attractiveness as an underlying mechanism between media and cognitive body image investment. Therefore, our research question is:

RQ1: Is a negative imbalance between benefits and costs associated with cognitive body image investment?

\section{The Importance of Peers in Early Adolescent Body Image}

Adolescents rarely encounter media content in isolation from their social environment. Rather, peers or friends provide crucial contexts for interpretation whereby behaviors occurring on screens can either be reinforced or discouraged (e.g., Fitzsimmons-Craft, 2011; Verheijen 
et al., 2018). It is theorized that peers - together with (social) media - can create an appearance culture in which appearance-related norms and expectations are communicated and reinforced (Jones et al., 2004; Scully et al., 2020). Research indicates that adolescents' peer experiences within this appearance culture affect their physical self-concept (Scully et al., 2020) and trigger weight-related behaviors, such as dieting or use of dietary supplements (Webb et al., 2014).

However, just as the power of peers to increase body image concerns has been demonstrated in prior research (e.g., Kenny et al., 2017), it can be argued that media-focused peer interactions could also attenuate the influence of idealized imagery (Webb et al., 2014). There are indications in the literature that having a friend who is unconcerned with weight (Rodin et al., 1990) or who talks against the thin ideal (Wertheim et al., 1997) serves as a protective factor in weight-loss behaviors (Shroff \& Thompson, 2006).

To understand the value of the agentic perspective on media processing, the current study will therefore examine whether early adolescents' media-focused interactions with peers (i.e., talking with peers about media and co-viewing) may also result in the balance/imbalance between benefits and costs for attractiveness and, as such, cognitive body image investment. The following set of hypotheses will be tested:

H3a: Media-focused interactions with peers are positively related to early adolescents' perception of benefits for attractiveness.

H3b: Media-focused interactions with peers are positively related to early adolescents' perception of costs for attractiveness.

\section{The Current Study}

The primary aim of the current study was to contribute to our understanding of how media use affects adolescents by taking an agentic perspective on media processing. With this perspective, we aim to acknowledge that adolescents encounter multiple media messages, tapping into both benefits and costs of a certain behavior or appearance. Next to merely 
encountering different messages, we advocate more scientific attention to the extent to which adolescents process this diverse information in their minds.

To achieve this aim, a three-wave panel study was conducted among early adolescents. A structural equation model was developed to empirically test the hypotheses on associations of media use and media-focused peer interactions with the perception of benefits and costs. To reach more valid explanations of the media-body image association, we argue that the intricacies of both perceived benefits and costs (i.e., interaction) should be recognized. To test how the balance / positive imbalance / negative imbalance between benefits and costs underlies the association between media and body image, polynomial regression analyses - allowing for curvilinear associations - were conducted.

As a final step in the validation of the proposed model for media processing, it should be acknowledged that early adolescents throughout their developmental stage are likely to make important progress in their evaluation and calibration of risk and reward (Steinberg, 2005). As such, the cognitive capability of early adolescents to draw benefits and costs from their media exposure and to weigh both before integrating the ideal in their self-concept might gradually increase with age. In other words, the agentic perspective on media processing may become a more adequate description of the media-body image association as adolescents age (RQ3). To that end, the moderating role of age was examined.

\section{Method}

\section{Participants and Sample Selection}

A three-wave panel study using a 6-month interval was conducted among 9 to 14-yearolds $^{1}$. In the fall of 2014, data were obtained from 39 schools from different parts of [country deleted] that agreed to participate in the study. Both the children and their parents were first informed about study aims, procedures, and confidentiality measures. After active parental

\footnotetext{
${ }^{1}$ This study presents a new and innovative approach to previously published data [anonimized]
} 
consent was obtained, early adolescents filled out three questionnaires in class during class hours. A researcher was present at all times to ensure optimal circumstances. No incentives were provided as is customary in [country deleted]. A total of 971 children (48.9\% girls) completed all three questionnaires. Across all three time points, children filled in the same measures in the same order. Respondents were re-contacted through their schools; some children transferred from elementary school (second wave) to middle school (third wave). In order to re-contact those children, parents were asked (during second wave) to provide a postal address to which a questionnaire together with a stamped envelope was sent (third wave). In all, 1976 children participated in wave 1, 1597 children participated in wave 2, and a total of 973 children completed all three questionnaires. Two respondents did not indicate their gender and were omitted from the analytical sample $(N=971)$. The mean age at baseline was 11.14 $(S D=1.13), 94.3 \%$ of the children were born in [country deleted]. Seventy-seven percent of the children (77\%) reported that their parents were married, $22.5 \%$ lived with divorced parents.

Differences were explored between the early adolescents who participated in one wave $(N=846)$, two waves $(N=867)$, and those who participated in all waves $(N=973)$ with regard to all relevant variables (at wave 1). A MANCOVA analysis (controlling for age, BMI, puberty, and gender) revealed that early adolescents who participated in only one wave, two waves, or all waves did not significantly differ on key variables, $F(14,3226)=1.61, p=.068, \eta p^{2}=.007$.

\section{Measures}

Control Variables. Participants completed questions about their gender (with $1=$ boy and $2=$ girl), age, and BMI (based on self-reported weight and height). In addition, puberty was added as a control variable considering that research indicates that pubertal maturation and social information-processing are linked (Steinberg, 2005). We measured participants' pubertal timing by using three items of the Pubertal Development Scale (Petersen, Crockett, Richards, 
\& Boxer, 1988). The items were "Describe the level of body hair growth," "Describe changes in complexion," and "Describe the development of voice change" (boys) or "Describe the development of breasts" (girls). Averaged items represent an estimate of pubertal timing.

Media Exposure. Using a 5-point scale ranging from "Never" $(=1)$ to "Almost every day" $(=5)$, participants first indicated how often they watched eight programs that are specifically created for the teen audience (i.e., Big Time Rush, H2O Just Add Water, Life With Boys, Wingin' It, Young Justice, Jessie, Austin \& Ally, and Violetta). These programs were chosen because of the popularity among children and content analytical work indicating the prevalence of idealized content (e.g., Northup \& Liebler, 2010). The programs were daily broadcast during the first wave of the study. An overall estimate of teen television exposure was obtained by averaging the item scores; Higher scores indicate more teen television exposure. Next, overall television exposure was measured by having participants indicate how frequently they watched television on a timeline. A timeline ranging from 7.00 AM to 2.00 AM was presented for each day of the week and for weekend-days or holidays. Each hour of the day was presented by two checkboxes representing thirty minutes and participants marked the checkboxes if they typically watch television at that moment of the day. The number of marked checkboxes per timeline was summed up and divided by two to get an estimate of total viewing hours per day. Additionally, the total hours indicated on the time line for weekend days was multiplied by two (i.e., two weekend days). We summed the total hours per timeline and divided the sum by seven (5 weekdays and 2 weekend days) to create an estimate of total television viewing per day. Participants were further asked to indicate how often they used Facebook, on a 7-point scale with "Never" (=1), "Less than one time per month" (=2), "One to three times per month" (= 3), "Once a week" (=4), "More than once a week" (= 5), "Every day" (=6), and "More than once every day" (=7). The same scale was used to measure the extent to which early adolescents searched online information about issues related to love (because of the strong 
sexualized context of appearance content [Ward, 2016]; item 1) and the body (item 2). Both items were averaged to get an overall estimate of participants' online information search.

Media-Focused Peer Interactions. Inspired by Beentjes and Konig's (2013) procedure, we asked participants to indicate their agreement with seven statements on a 5-point scale ranging from (1) "Totally disagree" to (5) "Totally agree." Items included "I watch television programs with my friends," "When I am with my friends, our conversations often involve famous men and/or women" and "My friends and I agree on which famous men and/or women are attractive." This scale showed good reliability $(\omega=.911)$. An overall estimate of media-focused peer interactions was created by averaging the item scores; Higher scores indicate more frequent media-focused peer interactions.

Benefits and Costs of Attractiveness. To measure participants' outcome expectancies of having an attractive appearance, a scale was developed. Participants were asked to imagine they looked like a person they find very attractive. Subsequently, using a scale ranging from $I$ totally disagree $(=1)$ to I totally agree $(=5)$, they indicated their agreement with five positive outcomes (i.e., being happier, being more self-confident, receiving more attention from friends and peers, thinking it would be easier to find a girl/boyfriend, and doing better in school) and three negative outcomes (i.e., same-sex friendships would suffer, same-sex individuals would be jealous, and being more preoccupied with appearance than school). Exploratory factor analysis extracted two factors; a factor with positive outcomes (eigenvalue $=3.434$ and explained variance $=42.922$ ) and a factor with negative outcomes (eigenvalue $=1.349$ and explained variance $=16.860)$. The positive outcomes subscale showed good reliability $(\omega=$ .822). The negative outcomes subscale showed only moderate reliability $(\omega=.666)$ but was retained because of its exploratory nature. A mean score was computed for both subscales.

Social Appearance Anxiety. The Social Appearance Anxiety Scale (Hart et al., 2008) was used to measure the extent to which early adolescents feared negative evaluations by others 
because of their overall appearance. The original scale consists of 16 items. Based on factor loadings and the poor understanding of some of the items, we decided to use 14 items of the original scale. Respondents indicated their agreement with items such as "I feel nervous when having my picture taken" and "I get tense when it is obvious people are looking at me" on a 5point scale ranging from I totally disagree $(=1)$ to I totally agree $(=5)$. In the current study, McDonald's Omega's for the SAAS was .905.

\section{Data Analysis Plan}

The hypothesized model was first tested through structural equation modeling in AMOS, using the maximum likelihood method. We used the chi-squared-to-degrees-offreedom ratio $\left(\chi^{2} / \mathrm{df}\right)$, the comparative fit index $(\mathrm{CFI})$, and the root mean square error of approximation (RMSEA) to address the fit of the model. Prior to these analyses, multiple imputation was performed as the bootstrapping method does not allow the sample to include missing values. Five-hundred and eighty-five participants had no missing values $(60.2 \%)$. Two-hundred and thirty-six participants $(24.3 \%)$ had only one missing value that had to be imputed. All variables had less than $10 \%$ missing data.

Next, we employed polynomial regression and response surface analysis (Edwards \& Parry, 1993) to help us understand the association between perceived benefits and costs (wave 2) and social appearance anxiety (wave 3). Whereas difference scores represent the relationship between two measures with a single score - thereby reducing an inherently three-dimensional relationship between three measures to two dimensions - polynomial regression enables researchers to investigate curvilinear relationships more accurately and allows more complex relationships which difference scores cannot represent. As such, multivariate regression analysis has limitations in accurately detecting how different combinations between benefits and costs can influence social appearance anxiety. It should be noted that we used scalecentered measures in the analysis (Edwards, 1994) to alleviate the threats of multi-collinearity 
between the component measures and their higher-order terms (Aiken \& West, 1991).

\section{Results}

\section{Descriptive Statistics and Preliminary Analyses}

Descriptive statistics and zero-order correlations were run for all variables (Table 1). [insert Table 1 here]

\section{Testing the Hypothesized Model}

To test the overall hypothesized model, a structural equation model (Figure 2) was developed where exposure to teen media shows and media-focused interactions with peers (both at wave 1) related to social appearance anxiety (wave 3), through benefits and costs (wave 2). The model yielded a chi-square value of 6681.83 with 2973 degrees of freedom, $p<.001$, $\mathrm{RMSEA}=.04, \mathrm{CFI}=.91 ; \chi^{2} / d f=2.25$. The results indicated that $22.5 \%$ of the variance of perceived costs and $32.2 \%$ of the variance of perceived benefits could be explained by the media and peer variables. Thirty-nine percent of the variance of social appearance anxiety could be explained by the media and peer variables, perceived benefits and costs, and the interaction between perceived benefits and costs.

\section{[insert Figure 2 here]}

The results revealed that only media-focused interactions with peers (wave 1) were significantly related to both perceived benefits and costs at wave $2(B=.06, \beta=.09, S E=.04$, $C I$ 95\%[.007, .170], $p=.028$ and $B=.09, \beta=.09, S E=.03, C I 95 \%[.029, .160], p=.011$, respectively). None of the media-variables were significantly related to perceived benefits and costs. Specifically, teen media exposure was unrelated to perceived benefits and costs $(B=.04$, $\beta=.06, S E=.04, C I 95 \%[-.008, .143], p=.088$ and $B=-.002, \beta=-.003, S E=.03, C I 95 \%[-$ $.068, .063], p=.927$, respectively). Facebook use was unrelated to perceived benefits and costs $(B=-.001, \beta=-.004, S E=.04, C I 95 \%[-.086, .079], p=.892$ and $B=.008, \beta=.022, S E=$ $.04, C I 95 \%[-.049, .089], p=.551$, respectively), as was online information searching $(B=$ 
$.029, \beta=.036, S E=.04, C I 95 \%[-.035, .111], p=.337$ and $B=.030, \beta=.026, S E=.03, C I$ $95 \%[-.037, .087], p=.444$, respectively). Lastly, overall television exposure was unrelated to perceived benefits and costs $(B=-.012, \beta=-.037, S E=.04, C I 95 \%[-.115, .037], p=.306$ and $B=.008, \beta=.017, S E=.03, C I 95 \%[-.040, .080], p=.535$, respectively).

Additionally, none of the peer and media variables were significantly related to the interaction between perceived benefits and costs. Specifically, media-focused peer interactions were unrelated to the interaction term $(B=-.009, \beta=-.016, S E=.05, C I 95 \%[-.102, .076], p$ $=.760)$. Teen media exposure $(B=-.009, \beta=-.015, S E=.05, C I 95 \%[-.104, .083], p=.719)$, online searching for information $(B=.025, \beta=.039, S E=.05, C I 95 \%[-.059, .138], p=.429)$, Facebook use $(B=.001, \beta=.003, S E=.05, C I 95 \%[-.104, .109], p=.950)$, and overall television exposure $(B=-.008, \beta=-.031, S E=.04, C I 95 \%[-.119, .057], p=.488)$ were unrelated to the interaction term.

The results further showed that none of the peer and media variables (all wave 1) were significantly related to social appearance anxiety (wave 3). Specifically, media-focused peer interactions were unrelated to the interaction term $(B=.026, \beta=.054, S E=.03, C I 95 \%[-.006$, $.114], p=.079)$. Teen media exposure $(B=-.008, \beta=-.021, S E=.03, C I 95 \%[-.082, .037], p$ $=.474)$, online searching for information $(B=.037, \beta=.068, S E=.03, C I 95 \%[.005, .122], p$ $=.033)$, Facebook use $(B=-.005, \beta=-.030, S E=.03, C I 95 \%[-.093, .032], p=.358)$, and overall television exposure $(B=-.005, \beta=-.022, S E=.03, C I 95 \%[-.078, .036], p=.480)$ were unrelated to the interaction term.

Perceived costs (wave 2) were, however, unrelated to social appearance anxiety (wave 3), $B=.027, \beta=.04, S E=.04, C I 95 \%[-.046, .124], p=.152$. Perceived benefits (wave 2) were only marginally significantly related to social appearance anxiety (wave 3 ), $B=.037, \beta$ $=.074, S E=.04, C I 95 \%[-.005, .161], p=.065$. The interaction between perceived benefits and costs (wave 2) was unrelated to social appearance anxiety (wave 3), $B=-.057, \beta=-.065$, 
$S E=.04, C I 95 \%[-.137, .023], p=.136$.

\section{Polynomial Regression and Surface Response Analysis}

To test hypotheses H2a, H2b, H4a, H4b, RQ1, and RQ2, we analyzed social appearance anxiety on the perfect balance and imbalance lines. For this, we employed polynomial regression and response surface analysis (Edwards \& Parry, 1993), an analysis technique developed to help analyze a construct with multiple components (e.g., $\mathrm{X}-\mathrm{Y}, \mathrm{X}+\mathrm{Y}, \mathrm{X} \mathrm{x} \mathrm{Y}$ ).

The first step in polynomial regression is a linear regression analysis, without the interaction between the standardized predictor variables and the squared standardized predictor variables. This linear regression analysis (controlling for BMI, gender, puberty, age, and prior levels of social appearance anxiety) indicated that only perceived benefits $(\beta=.07, t=2.00, p$ $=.046)$ but not costs $(\beta=.04, t=1.49, p=.136)$ at wave 2 were significantly related to social appearance anxiety (wave 3$), R=.65, R^{2}=.41, F(7,847)=87.46, p<.001$.

Next, a hierarchical polynomial regression and surface response analysis of the interaction between perceived benefits and costs (wave 2) on social appearance anxiety (wave 3) was performed (controlling for BMI, gender, puberty, age, and prior levels of social appearance anxiety). The results indicated that $R^{2}$ did not significantly increase when adding the product of the standardized predictor variables and the squared standardized predictor variables into the regression equation. However, both the squared standardized perceived costs and the interaction term reached significance. Therefore, we performed a response surface analysis and graphed our results (see Figure 3). This analysis revealed that the surface under the incongruence line $(\mathrm{X}=-\mathrm{Y})$ curved upward (curvature; $B=.13, S E=.05, \mathrm{p}<.05)$. Figure 3 indicates that there is a U-shaped line along the incongruence line (i.e., the line from the left front corner to the right rear corner). The curvature along the $\mathrm{X}=-\mathrm{Y}$ line indicates that social appearance anxiety is lowest when early adolescents' perceived benefits and costs are aligned, and any deviation from the congruence line - thus moving more to its right or left increases 
social appearance anxiety, 6 months later.

In addition, the slope of the incongruence line (slope; $B=.13, S E=.06, \mathrm{p}<.05$ ) is positive, indicating a shift toward the region where $\mathrm{X}$ is higher than $\mathrm{Y}$. In other words, when early adolescents' perceived costs are higher than the perceived benefits, social appearance anxiety increases more sharply than it does when adolescents' perceived costs are lower than their perceived benefits. This effect is visualized in Figure 3, in which social appearance anxiety is lower at the left front corner (where $\mathrm{X}=-2$ and $\mathrm{Y}=2$ ) than at the right rear corner (where $\mathrm{X}=2$ and $\mathrm{Y}=-2$ ).

[insert Figure 3 here]

\section{Differences According to Age}

In a last step, we performed the polynomial regression and response surface analysis in three age groups, 9 - to 10 -year-olds $(N=367,37.8 \%), 11$-year-olds $(N=251,25.8 \%)$, and 12 to 14 -year-olds $(N=353,36.4 \%)$. These analyses revealed that, among 9 - to 10 -year-olds, there was no significant polynomial association between perceived benefits and costs (wave 2) on the one hand and social appearance anxiety (wave 3) on the other hand, $\Delta R^{2}=.01, p=.115$. Although $\Delta R^{2}$ was also insignificant ( $p=.315$ ) in the second group (i.e., 11-year-olds), the results did show that the standardized perceived costs were significantly related to the dependent variable $(B=.192, S E=.081, p=.019)$. A surface response analysis showed that the slope of the congruence line was significant (slope $\mathrm{X}=\mathrm{Y} ; B=.21, S E=.10, p<.05$ ), indicating a significant linear association between benefits and costs and social appearance anxiety. In other words, 11-year-olds report higher levels of social appearance anxiety (wave 3) when they simultaneously perceive more benefits and costs of attractiveness. Lastly, among 12- to 14-year-olds, it was found that $\Delta R^{2}$ was again insignificant $(p=.130$ ), but the interaction between the standardized predictor variables was significant $(B=-.115, S E=.048, p=.019)$. The surface response analysis revealed that the surface under the incongruence line $(\mathrm{X}=-\mathrm{Y})$ 
curved upward (curvature; $B=.24, S E=.09, p<.01$ ). As shown in Figure 4, there is a Ushaped line along the incongruence line (i.e., the line from the left front corner to the right rear corner) among 12- to 14-year-olds. The curvature along the $\mathrm{X}=-\mathrm{Y}$ line indicates that social appearance anxiety is lowest when early adolescents' perceived benefits and costs are aligned, and any deviation from the congruence line - thus moving more to its right or left increases social appearance anxiety, 6 months later.

[insert Figure 4 here]

\section{Discussion}

The overall aim of the current study was to add to media effects research a complexity that is believed to be inherent to media use, namely the presence of multiple and possibly opposing messages. One media context in which both are explicitly present is that of idealized appearances. By taking an agentic perspective on media processing, the current study explored whether the complex interaction between the perceived benefits and costs of being appearance focused serves as a mechanism underlying the association between media exposure and body image investment. The findings offer several important insights and stress the merits of assessing the variable vulnerability of early adolescents to the media effect.

First, peer interactions seem to provide a particularly strong context for multi-layered media ideals to affect adolescents' self-concept, certainly within the context of body image investment. More specifically, media-focused interactions with peers color adolescents' positive and negative perceptions of ideals, whereas media exposure in and of itself does not. This particular finding aligns with audience research that awards great importance to the social settings in which media consumption usually takes place (Morley, 1993). More specifically, it is argued that the interpretation of media content is dependent on a framework of references of the viewer, rendering media consumption and reception an activity that is embedded within the interpersonal context (Moores, 1993). Acknowledging adolescents' agency in navigating 
through multiple and possibly opposing messages thus seems especially valuable for media content, if it has been digested within the social context.

Notably, the findings seem to point out that early adolescents were more likely to derive both positive and negative perceptions regarding appearance ideals from peer encounters. From this finding, we could carefully infer that peers may be a more important source of such diverse messages. The current study, however, did not directly measure early adolescents' encounter with conflicting messages, necessitating future studies to further disentangle this reality.

For the integration of multi-layered ideals into one's self-concept, the current findings indicate that the unique intertwining between idealized and counter-idealized perceptions should be interpreted as a U-shaped continuum. The current study's application of the agentic perspective on body image in particular shows that an alignment of these perceptions is not associated with body image, whereas a deviation from this balanced state - in either direction - does entail a negative influence on body image.

It follows that both negative and positive perceptions should be assessed simultaneously in order to adequately understand the dynamics of the media effect. Overlooking the complex interplay of endorsing multi-layered ideals might hinder an identification of risk groups. Specifically, the findings reveal that early adolescents may be less affected by idealized imagery when the cognitive process of weighing the benefits and costs results in a balanced state between both perceptions. The current study thus shows, for the first time, that outcome expectancies can cancel each other out and, as such, attenuate the influence of idealized imagery on self-concept in general and body image investment in particular. Any deviation from the balanced state related to higher body image investment: Both a positive and negative imbalance seem to put adolescents at risk of overvaluing their appearance in social encounters. Our findings are thereby in line with traditional media effects research in assuming that 
adolescents buy into the glorifying setting in which media ideals are presented. Following social cognitive theory (Bandura, 2001) and prior studies (e.g., Trekels et al., 2018), it was found that the reinforcement of media ideals affects adolescents' motivation to personally endorse the ideal. At the same time, however, the current study nuances this traditional viewpoint on the media effect by showing that a negative imbalance - a state in which the perceived costs outweigh the benefits - also increases body image investment. The result for the negative imbalance coincide with indications in the literature that positive body image campaigns, including feel-good advertisements, are associated with both positive feelings and thoughts as well as negative emotional responses (e.g., Kraus \& Myrick, 2018). In particular, content that aims to help viewers feel satisfied with their appearance might actually prime them to think about their appearance, thereby inducing body dissatisfaction. Accordingly, it could be argued that counter-idealized content, despite its intent to put appearance in perspective, actually contradictorily foregrounds appearance. Adolescents' perceptions of costs for attractiveness correspond to their belief that certain outcomes (jealousy or less time for school) are a direct derivative of one's appearance. Consequently, appearance is still awarded a central role, possibly resulting in an investment in their body image.

The differential influence of balanced vs imbalanced states on body image investment highlights the importance of what adolescents bring to the processing and evaluating of content they are - indirectly through peers - exposed to. Specifically, an important conclusion that accompanies the observation that adolescents may be disinclined to incorporate media ideals in their self-concept is that it nuances the vulnerability of adolescents to the media effect and, as such, can proof to be an important guide in developing effective interventions. As such, this study's findings add to the current literature's stance in the need to disentangle the media effect as within-person associations (Beyens et al., 2020) and to take account of what individuals add to the examined media effect. By incorporating individual and situational characteristics, this 
study shows that individuals may incorporate different types of messages in different ways (i.e., balance vs imbalance), which helps contextualize previous mixed findings.

A final contribution of the current study refers to the developmental phase in which the agentic perspective on media processing was examined. The findings indicate that, over the course of the developmental phase, early adolescents' ability to calibrate idealized and counteridealized messages improves. It was found that the cognitive process of weighing the perceived benefits and costs for being appearance focused was more likely to be related to body image investment, among the older adolescents. For the youngest adolescents in the sample (i.e., 9to 10-year-olds), no significant association was found between the interaction and body image investment, indicating that they did not seem to weigh the benefits against the costs (or vice versa) upon integrating media ideals in their self-concept. For 11-year-olds, the results pointed out that perceiving more benefits and costs simultaneously increased body image investment. This finding thus indicates that 11-year-olds do not appear to weigh the benefits and costs, but rather become more invested in their body image when they perceive both benefits and costs to a higher degree. However, 12- to 14-year-olds did appear to engage in a process of cognitive evaluation and processing of diverse information in their minds. The results indicated that body image investment was lowest in a balanced state and that imbalance between the perceived benefits and costs increased social appearance anxiety. As such, the agentic perspective on media processing seems to be a more adequate description of the media-body image association, as adolescents age.

The current study is not without its limitations. First, despite the longitudinal study design, our conclusions are limited to observed associations between the examined concepts. Conclusions about the causal links between media exposure and body image investment and the explanatory role of balance vs imbalance state cannot be drawn from the current study. Experimental research examining whether exposure to multi-layered media ideals, for instance 
a positive Instagram post with unfavorable comments, leads to perceptions about both the positive and negative consequences of complying with the ideal and, in turn, ideal investment are necessary. Moreover, it should be noted that the agentic perspective on media effects posited in the current study does not necessarily assume conscious acts of media processing. Experimental research is necessary for testing the unconscious reactions of adolescents to diverse media messages. Second, the use of self-report measures might have biased our results to some extent. Specifically, early adolescents might have had difficulty estimating how often they consumed media, discussed media content with their peers, or how strongly they consider appearance to be important in social interactions. Lastly, social appearance anxiety was considered as a proxy for body image investment in the current study. Other concepts that also tap into the value that is attached to appearance (e.g., appearance-based self-worth) might be considered in future research to broaden our understanding of the dynamics that are involved in the cognitive processing and evaluation of multi-layered media ideals.

\section{Conclusion}

The present study contributes to current literature by introducing an agentic perspective on media processing and acknowledging that adolescents are not merely exposed to idealized imagery but to counter- or disillusioning messages as well. Such diverse messages seemed primarily encountered through peer interactions rather than through direct media exposure. Importantly, by accounting for curvilinear associations, the current study adds an important nuance to contemporary media effects perspectives in general and body image in particular. Specifically, findings pointed out that early adolescents might not integrate media ideals (or counter-ideals) in their self-concept when they believe equally strongly in the counter-ideals (or ideals). However, either imbalance between idealized and counter-idealized impressions did relate to self-concept. As such, the findings might be a fruitful guide in developing effective interventions by exposing a variable vulnerability to media effects. 


\section{References}

Bandura, A. (1989). Human agency in social cognitive theory. American Psychologist, 44, $1175-1184$.

Bandura, A. (2001). Social cognitive theory: An agentic perspective. Annual Review of Psychology, 52, 1-26. https://doi.org/10.1146/annurev.psych.52.1.1

Beentjes, J., \& Konig, R. (2013). Does exposure to music videos predict adolescents' sexual attitudes? European Scientific Journal, 9, 1-20. Retrieved from http://www.eujournal.org/index.php/esj/article/view/1066

Betz, D. E., \& Ramsey, L. R. (2017). Should women be “ All About That Bass ?”: Diverse body-ideal messages and women's body image. Body Image, 22, 18-31. https://doi.org/10.1016/j.bodyim.2017.04.004

Beyens, I., Pouwels, J. L., van Driel, I. I., Keijsers, L., \& Valkenburg, P. M. (2020). the effect of social media on well-being differs from adolescent to adolescent. Scientific Reports, 10: 10763. https://doi.org/10.1038/s41598-020-67727-7

Biocca, F. A. (1988). Opposing Conceptions of the Audience: The Active and Passive Hemispheres of Mass Communication Theory. Annals of the International Communication Association, 11, 51-80. https://doi.org/10.1080/23808985.1988.11678679

Burnette, C. B., Kwitowski, M. A., \& Mazzeo, S. E. (2017). “I don’t need people to tell me I'm pretty on social media:" A qualitative study of social media and body image in early adolescent girls. Body Image, 23, 114-125. https://doi.org/10.1016/j.bodyim.2017.09.001

Calogero, R. M., Pina, A., Park, L. E., \& Rahemtulla, Z. (2010). Objectification Theory Predicts College Women's Attitudes Toward Cosmetic Surgery. Sex Roles, 63, 32-41. https://doi.org/10.1007/s11199-010-9759-5 
Clark, L., \& Tiggemann, M. (2006). Appearance culture in nine- To 12-year-old girls: Media and peer influences on body dissatisfaction. Social Development, 15, 628-643. https://doi.org/10.1111/j.1467-9507.2006.00361.x

Clayton, R. B., Ridgway, J. L., \& Hendrickse, J. (2017). Is plus size equal? The positive impact of average and plus-sized media fashion models on women's cognitive resource allocation, social comparisons, and body satisfaction. Communication Monographs, 84, 406-422. https://doi.org/10.1080/03637751.2017.1332770

Cohen, R., Irwin, L., Newton-John, T., \& Slater, A. \#Bodypositivity: A content analysis of body positive accounts on Instagram. Body Image, 29, 47-57. https://doi.org/10.1016/j.bodyim.2019.02.007

Daniels, E. A., \& Zurbriggen, E. L. (2016). The Price of Sexy : Viewers' Perceptions of a Sexualized Versus Nonsexualized Facebook Profile Photograph. Psychology of Popular Media Culture, 5, 2-14. https://doi.org/10.1037/ppm0000048

Edwards, J. R., \& Parry, M. E. (1993). On the use of polynomial regression equations as an alternative to difference scores in organizational research. Academy of Management Journal, 36, 1577-1613. https://doi.org/10.2307/256822

Festinger, L. (1962). A theory of cognitive dissonance. Stanford University: Stanford Fischer, P., Greitemeyer, T., Kastenmüll:er, A., Vogrincic, C., \& Sauer, A. (2011). The Effects of Risk-Glorifying Media Exposure on Risk-Positive Cognitions, Emotions, and Behaviors: A Meta-Analytic Review. Psychological Bulletin, 137, 367-390. https://doi.org/10.1037/a0022267

Fitzsimmons-Craft, E. E. (2011). Social psychological theories of disordered eating in college women: Review and integration. Clinical Psychology Review, 31, 1224-1237. https://doi.org/10.1016/j.cpr.2011.07.011

Gleeson, K., \& Frith, H. (2006). (De)constructing Body Image. Journal of Health 
Psychology, 11, 79-90. https://doi.org/10.1177/1359105306058851

Graff, K., Murnen, S. K., \& Smolak, L. (2012). Too sexualized to be taken seriously? Perceptions of a girl in childlike vs. sexualizing clothing. Sex Roles, 66, 764-775. https://doi.org/10.1007/s11199-012-0145-3

Groesz, L. M., Levine, M. P., \& Murnen, S. K. (2002). The effect of experimental presentation of thin media images on body satisfaction: a meta-analytic review. The International Journal of Eating Disorders, 31, 1-16. https://doi.org/10.1002/eat.10005

Hart, T. A., Flora, D. B., Palyo, S. A., Fresco, D. M., Holle, C., \& Heimberg, R. G. (2008). Development and examination of the social appearance anxiety scale. Assessment, 15, 48-59. https://doi.org/10.1177/1073191107306673

Harter, S. (2015). The construction of the self: Developmental and sociocultural foundations. Guilford Press.

Jones, D. C., Vigfusdottir, T. H., \& Lee, Y. (2004). Body image and the appearance culture among adolescent girls and boys: An examination of friend conversations, peer criticism, appearance magazines, and the internalization of appearance Ideals. Journal of Adolescent Research, 19, 323-339. https://doi.org/10.1177/0743558403258847

Kenny, U., O'Malley-Keighran, M-P., Molcho, M., \& Kelly, C. (2017). Peer influences on adolescent body image: Friends or foes? Journal of Adolescent Health, 32, 768-799. https://doi.org/10.1177/0743558416665478

Kleemans, M., Daalmans, S., Carbaat, I., \& Anschïtz, D. (2018). picture perfect: The direct effect of manipulated Instagram photos on body image in adolescent girls. Media Psychology, 21, 93-110. https://doi.org/10.1080/15213269.2016.1257392

Knobloch-Westerwick, S. (2014). Choice and preference in media use. Advances in selective exposure theory and research. Routledge. 
Kraus, A., \& Myrick, J. G. (2018). Feeling Bad About Feel-Good Ads: The Emotional and Body-Image Ramifications of Body-Positive Media. Communication Research Reports, 35, 101-111. https://doi.org/10.1080/08824096.2017.1383233

Livingstone, S. (1998). Making sense of television. The psychology of audience interpretation. Routledge.

McCabe, M. P., Connaughton, C., Tatangelo, G., Mellor, D., \& Busija, L. (2017). Healthy me: A gender-specific program to address body image concerns and risk factors among preadolescents. Body Image, 20, 20-30. https://doi.org/10.1016/j.bodyim.2016.10.007

Moores, S. (1993). Interpreting audiences. The ethnography of media consumption. SAGE Publications Ltd.

Morley, D. (1993). Active audience theory: Pendulums and pitfalls. Journal of Communication, 43, 13-19. https://doi.org/10.1111/j.1460-2466.1993.tb01299.x

Mulgrew, K. E., McCulloch, K., Farren, E., Prichard, I., \& Lim, M. S. C. (2018). This girl can \#jointhemovement: Effectiveness of physical functionality-focused campaigns for women's body satisfaction and exercise intent. Body Image, 24, 26-35. https://doi.org/10.1016/j.bodyim.2017.11.007

Nabi, R. L., \& Clark, S. (2008). Exploring the limits of social cognitive theory: Why negatively reinforced behaviors on TV may be modeled anyway. Journal of Communication, 58, 407-427. https://doi.org/10.1111/j.1460-2466.2008.00392.x

Nelson, A. A., \& Brown, C. S. (2018). Too pretty for homework: Sexualized gender stereotypes predict academic attitudes for gender-typical early adolescent girls. Journal of Early Adolescence, 1-15. https://doi.org/10.1177/0272431618776132

Northup, T., \& Liebler, C. M. (2010). The good, the bad, and the beautiful. Journal of Children and Media, 4, 265-282. https://doi.org/10.1080/17482798.2010.496917 
Paxton, S. J., Schutz, H. K, Wertheim, E. H., \& Muir, S. L. (1999). Friendship clique and peer influences on body image concerns, dietary restraint, extreme weight-loss behaviors and binge eating in adolescent girls. Journal of Abnormal Psychology, 108, 255-266.

Petersen, A. C., Crockett, L., Richards, M., \& Boxer, A. (1988). A self-report measure of pubertal status: Reliability, validity, and initial norms. Journal of Youth and Adolescence, 17, 117-133. https://doi.org/10.1007/BF01537962

Rodgers, R. F., Paxton, S. J., \& Wertheim, E. H. (2021). \#Take idealized bodies out of the picture: A scoping review of social media content aiming to protect and promote positive body image. Body Image, 38, 10-36. https://doi.org/10.1016/j.bodyim.2021.03.009

Rodin, J., Silberstein, L., \& Striegel-Moore, R. (1985). Women and weight: A normative discontent. In T. B. Sonderegger (Ed.), Psychology and gender. (pp. 267-307). University of Nebraska Press.

Rubin, A. M. (1994). Media uses and effects: A uses-and-gratifications perspective. In J. Bryant \& D. Zillmann (Eds.), Media effects: Advances in theory and research (pp. 417-436). Lawrence Erlbaum Associates, Inc.

Saiphoo, A. N. \& Vahedi, Z. (2019). A meta-analytical review of the relationship between social media use and body image disturbance. Computers in Human Behavior, 101, 259-275. https://doi.org/10.1016/j.chb.2019.07.028

Scott, J. F. (1971). Internalization of norms: A sociological theory of moral commitment. Prentice-Hall.

Scully, M., Swords, L., \& Nixon, E. (2020). social comparisons on social media: online appearance-related activity and body dissatisfaction in adolescent girls. Irish Journal of Psychological Medicine (online first publication). 
https://doi.org/10.1017/ipm.2020.93

Shroff, H., \& Thompson, J. K. (2006). Peer influences, body-image dissatisfaction, eating dysfunction and self-esteem in adolescent girls. Journal of Health Psychology, 11, 533-551. https://doi.org/10.1177/1359105306065015

Slater, A., Tiggemann, M., Firth, B., \& Hawkins, K. (2012). Reality Check: An Experimental Investigation of the Addition of Warning Labels to Fashion Magazine Images on Women's Mood and Body Dissatisfaction. Journal of Social and Clinical Psychology, 31, 105-122. https://doi.org/10.1521/jscp.2012.31.2.105

Smith, S. M., Fabrigar, L. R., \& Norris, M. E. (2008). Reflecting on Six Decades of Selective Exposure Research: Progress, Challenges, and Opportunities. Social and Personality Psychology Compass, 2, 464-493. https://doi.org/10.1111/j.1751-9004.2007.00060.x

Steinberg, L. (2005). Cognitive and affective development in adolescence. Trends in Cognitive Sciences, 9, 69-74. https://doi.org/10.1016/j.tics.2004.12.005

Tiggemann, M., Hayden, S., Brown, Z., \& Veldhuis, J. (2018). The effect of Instagram “likes" on women's social comparison and body dissatisfaction. Body Image, 26, 9097. https://doi.org/10.1016/j.bodyim.2018.07.002

Trekels, J. (2018). The ubiquity of beauty-is-good in media: Understanding the importance of appearance in adolescents' lives [Doctoral dissertation, University of Leuven]. Lirias. https://lirias.kuleuven.be/retrieve/510556

Trekels, J., \& Eggermont, S. (2017). Beauty is Good: The Appearance Culture, the Internalization of Appearance Ideals, and Dysfunctional Appearance Beliefs Among Tweens. Human Communication Research, 43, 173-192. https://doi.org/10.1111/hcre.12100

Trekels, J., Karsay, K., Vandenbosch, L. \& Eggermont, S. (2018). How social and mass media relate to youth's self-sexualization: Taking a cross-national perspective on 
rewarded appearance ideals. Journal of Youth and Adolescence, 47 (7), 1440-1455. https://doi.org/10.1007/s10964-018-0844-3

Verheijen, G. P., Burk, W. J., Stoltz, S. E. M. J., van den Berg, Y. H. M., \& Cillessen, A. H. N. (2018). Friendly fire: Longitudinal effects of exposure to violent video games on aggressive behavior in adolescent friendship dyads. Aggressive Behavior, 257-267. https://doi.org/10.1002/ab.21748

Ward, L. M. (2016). Media and Sexualization: A state of empirical research, 1995 - 2015. Journal of Sex Research, 53, 560-577. https://doi.org/10.1080/00224499.2016.1142496

Ward, L. M., Day, K. M., \& Epstein, M. (2006). Uncommonly good: Exploring how mass media may be a positive influence on young women's sexual health and development. New Directions for Child and Adolescent Development, 112, 57-70. https://doi.org/10.1002/cd.162

Webb, H. J., Zimmer-Gembeck, M. J., \& Donovan, C. L. (2014). The appearance culture between friends and adolescent appearance-based rejection sensitivity. Journal of Adolescence, 37, 347-358. https://doi.org/10.1016/j.adolescence.2014.02.008

Wertheim, E. H., Paxton, S. J., Schutz, H. K., \& Muir, S. L. (1997). Why do adolescent girls watch their weight? An interview study examining sociocultural pressures to be thin. Journal of Psychosomatic Research, 42, 345-355. https://doi.org/10.1016/S00223999(96)00368-6

Wigfield, A., \& Eccles, J. S. (2000). Expectancy-value theory of achievement motivation. Contemporary Educational Psychology, 25, 68-81. https://doi.org/10.1006/ceps.1999.1015

Zillmann, D., \& Bryant, J. (1985). Selective-exposure phenomena. In D. Zillmann \& J. Bryant (Eds.), Selective exposure to communication (pp. 1-33). Lawrence Erlbaum. 
Zsakai, A., Karkus, Z., Utczas, K., \& Bodzsar, E. B. (2017). Body Structure and Physical Self-Concept in Early Adolescence. Journal of Early Adolescence, 37, 316-338. https://doi.org/10.1177/0272431615602757

Zuair, A. A., \& Sopory, P. (2020). Effects of media health literacy school-based interventions on adolescents' body image concerns, eating concerns, and thin-internalization attitudes: A systematic review and meta-analysis. Health Communication (online first publication). https://doi.org/10.1080/10410236.2020.1813954 
Table 1

Descriptive statistics and zero-order correlations

\begin{tabular}{|c|c|c|c|c|c|c|c|c|c|c|c|c|c|c|c|}
\hline & 1 & 2 & 3 & 4 & 5 & 6 & 7 & 8 & 9 & 10 & 11 & 12 & 13 & 14 & 15 \\
\hline $\begin{array}{l}\text { 1. Teen media exposure } \\
\text { (wave 1) }\end{array}$ & & $.14^{* * * *}$ & $.16^{* * *}$ & $.14^{* * *}$ & $.14^{* * * *}$ & $.07^{*}$ & $.09^{* * *}$ & $.08^{* *}$ & $.16^{* * *}$ & $.10^{* *}$ & $.10^{* * * *}$ & $.23^{* * *}$ & .05 & -.04 & .05 \\
\hline $\begin{array}{l}\text { 2. Media-focused peer } \\
\text { interactions (wave 1) }\end{array}$ & & & $.27^{* * *}$ & $.20^{* * *}$ & $.21^{* * * *}$ & $.24^{* * * *}$ & $.21^{* * * *}$ & $.19^{* * * *}$ & $.25^{* * * *}$ & $.22^{* * * *}$ & $.22^{* * * *}$ & .04 & $.21^{* * * *}$ & $.16^{* * *}$ & .02 \\
\hline 3. Online appearance search & & & & $.23^{* * *}$ & $20^{* * * *}$ & $.16^{* * *}$ & $.16^{* * *}$ & $.12^{* * * *}$ & $.22^{* * *}$ & $.18^{* * *}$ & $.20^{* * * *}$ & .03 & $.14^{* * *}$ & .06 & .06 \\
\hline 4. Overall Facebook use & & & & & $.13^{* * *}$ & $.13^{* * *}$ & $.13^{* * *}$ & $.10^{* *}$ & $.12^{* * *}$ & $.15^{* * *}$ & $.11^{* * * *}$ & $-.07^{*}$ & $.22^{* * *}$ & $.43^{* * *}$ & $.18^{* * *}$ \\
\hline 5. Perceived benefits (wave 1 ) & & & & & & $.39^{* * *}$ & $.51^{* * *}$ & $.25^{* * * *}$ & $.49^{* * *}$ & $.40^{* * * *}$ & $.33^{* * * *}$ & .01 & $.17^{* * * *}$ & $.07^{*}$ & $.16^{* * *}$ \\
\hline 6. Perceived costs (wave 1 ) & & & & & & & $.26^{* * *}$ & $.34^{* * * *}$ & $.35^{* * *}$ & $.31^{* * * *}$ & $.25^{* * *}$ & -.01 & $.10^{* *}$ & $.16^{* * *}$ & $.13^{* * *}$ \\
\hline $\begin{array}{l}\text { 7. Perceived benefits (wave } \\
\text { 2) }\end{array}$ & & & & & & & & $.42^{* * * *}$ & $.37^{* * *}$ & $.54^{* * *}$ & $.41^{* * * *}$ & .03 & $.12^{* * * *}$ & $.11^{* * *}$ & $.11^{* * * *}$ \\
\hline 8. Perceived costs (wave 2) & & & & & & & & & $.24^{* * *}$ & $.38^{* * *}$ & $.30^{* * *}$ & .01 & $.08^{*}$ & $.18^{* * *}$ & $.08^{*}$ \\
\hline $\begin{array}{l}\text { 9. Social appearance anxiety } \\
\text { (wave 1) }\end{array}$ & & & & & & & & & & $.63^{* * * *}$ & $.54^{* * * *}$ & $.78^{* * * *}$ & $.18^{* * * *}$ & $.08^{*}$ & $.18^{* * * *}$ \\
\hline $\begin{array}{l}\text { 10. Social appearance } \\
\text { anxiety (wave 2) }\end{array}$ & & & & & & & & & & & $.63^{* * *}$ & $.17^{* * * *}$ & $.16^{* * *}$ & $.15^{* * *}$ & $.16^{* * *}$ \\
\hline $\begin{array}{l}\text { 11. Social appearance } \\
\text { anxiety (wave } 3 \text { ) }\end{array}$ & & & & & & & & & & & & $.19^{* * *}$ & $.15^{* * *}$ & $.13^{* * *}$ & $.16^{* * * *}$ \\
\hline 12. Gender & & & & & & & & & & & & & $.11^{* * * *}$ & $-.07^{*}$ & -.06 \\
\hline 13. Puberty & & & & & & & & & & & & & & $.28^{* * *}$ & $.21^{* * *}$ \\
\hline 14. Age & & & & & & & & & & & & & & & $.23^{* * *}$ \\
\hline 15. BMI & & & & & & & & & & & & & & & \\
\hline Range & $1-5$ & $1-5$ & $1-7$ & $1-7$ & $1-5$ & $1-5$ & $1-5$ & $1-5$ & $1-5$ & $1-5$ & $1-5$ & $1-2$ & $1-4$ & $9-14$ & $\begin{array}{l}9.6- \\
31.5\end{array}$ \\
\hline$M(S D)$ & $\begin{array}{c}2.34 \\
(1.06)\end{array}$ & $\begin{array}{l}2.31 \\
(.89)\end{array}$ & $\begin{array}{l}1.24 \\
(.76)\end{array}$ & $\begin{array}{c}3.20 \\
(2.48)\end{array}$ & $\begin{array}{l}2.75 \\
(.96)\end{array}$ & $\begin{array}{l}1.94 \\
(.81)\end{array}$ & $\begin{array}{c}2.73 \\
(1.04)\end{array}$ & $\begin{array}{l}1.96 \\
(.83)\end{array}$ & $\begin{array}{l}2.14 \\
(.71)\end{array}$ & $\begin{array}{l}2.09 \\
(.75)\end{array}$ & $\begin{array}{l}2.08 \\
(.77)\end{array}$ & I & $\begin{array}{l}1.78 \\
(.71)\end{array}$ & $\begin{array}{l}11.14 \\
(1.13)\end{array}$ & $\begin{array}{l}17.00 \\
(2.73)\end{array}$ \\
\hline
\end{tabular}




\section{Sociocultural Factors}
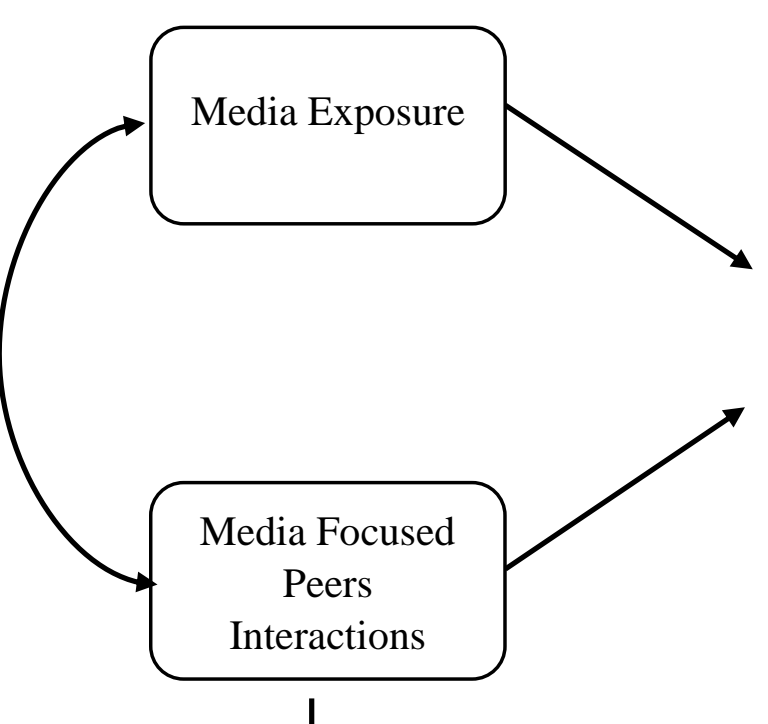

Balance/Imbalance

Benefits-Cost

\section{Cognitive Body Image}

Investment

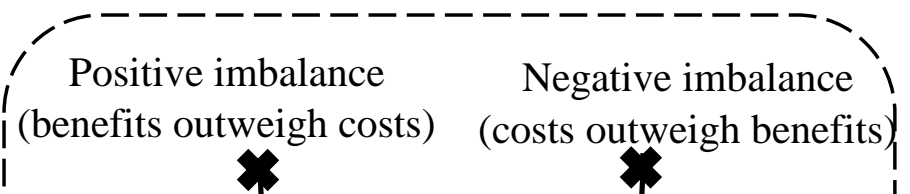

(costs outweigh benefits)

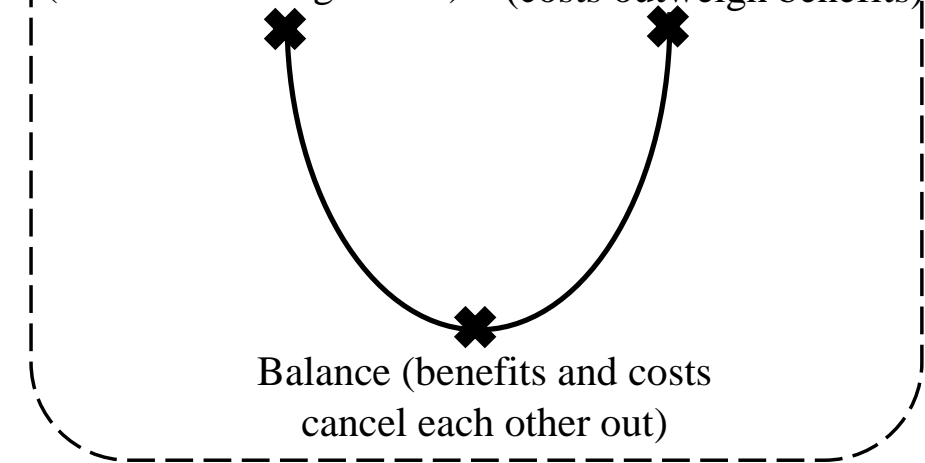

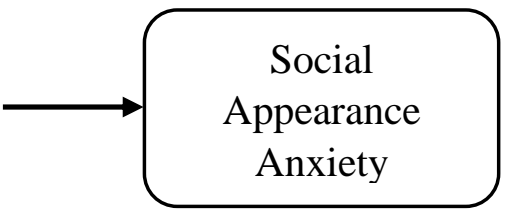

Figure 1. Hypothesized model for the relationships between sociocultural factors, balance/imbalance types, and social appearance anxiety. 


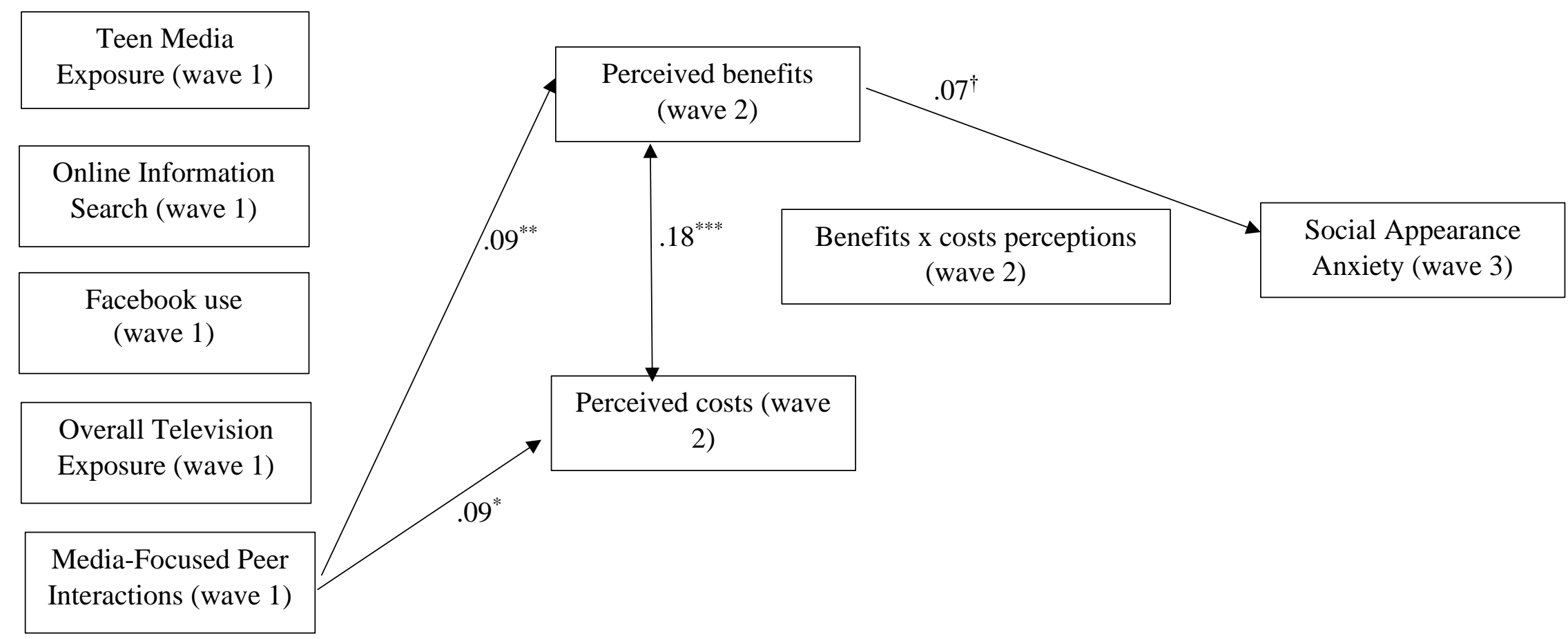

Figure 2. Structural equation model for the relationships between teen television exposure, peer discussions about media, perceived benefits, perceived costs, and social appearance anxiety $(N=971)$.

Note. Values reflect standardized coefficients (beta). Only significant paths are shown $\left({ }^{*} p<.05,{ }^{*} p<.01,{ }^{* * *} p<.001,{ }^{\dagger} \mathrm{p}<.10\right)$. 


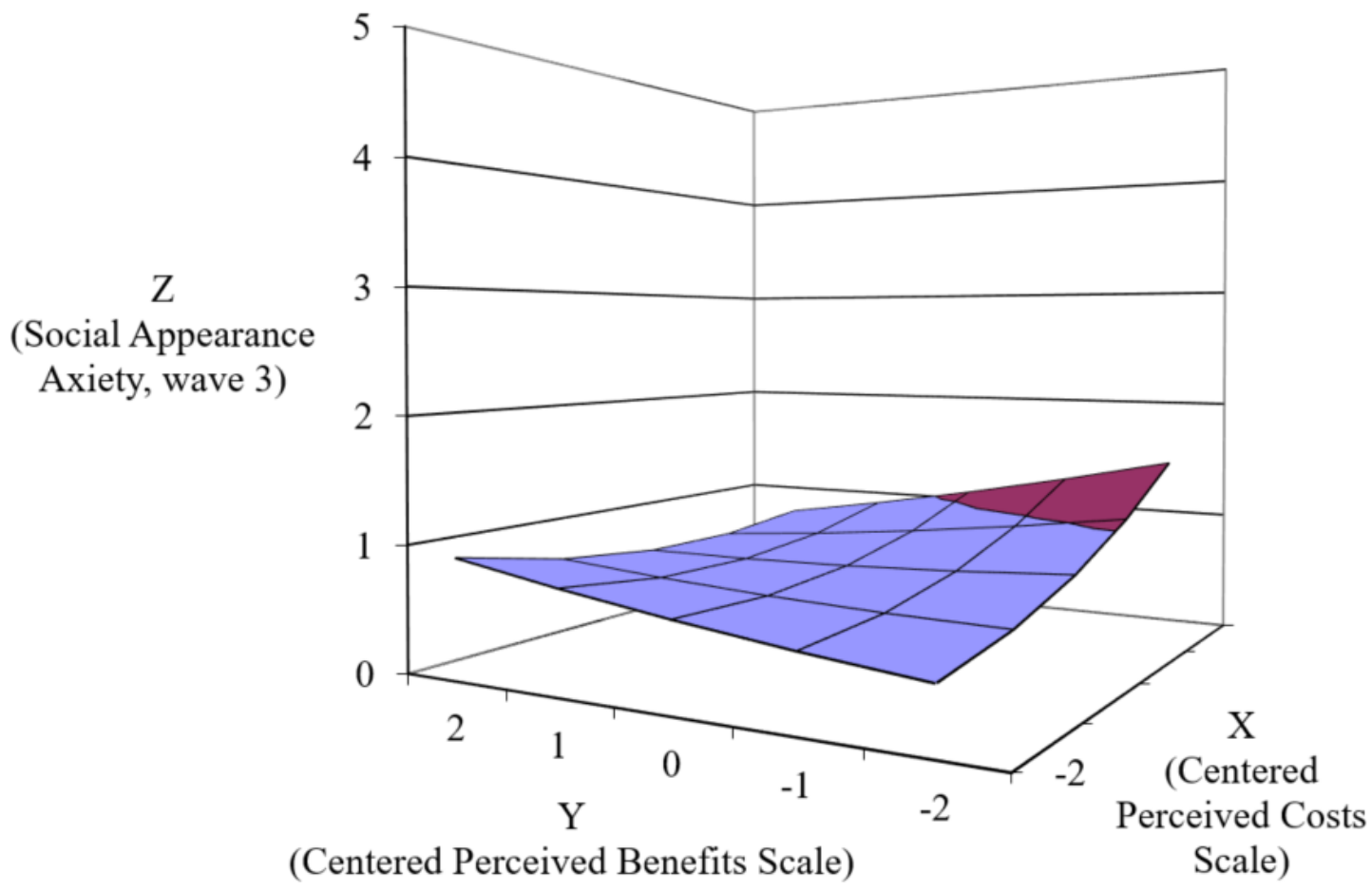

Figure 3. Results of the Response Surface Analysis for Social Appearance Anxiety as Predicted by Perceived Benefits - Perceived Costs Discrepancy. 
9- to 10-year-olds

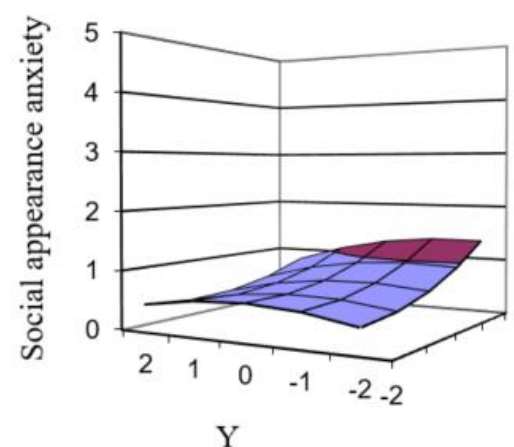

(centered perceived benefits scale) 11-year-olds

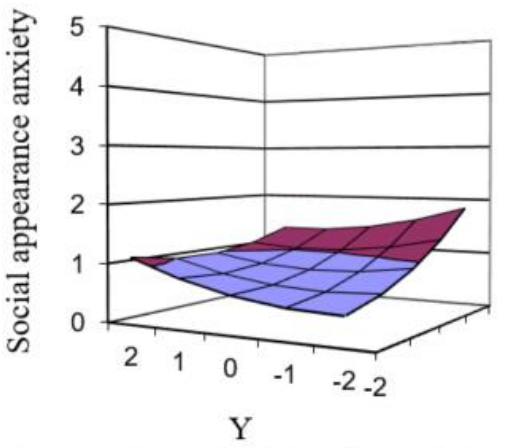

(centered perceived benefits scale)
12- to 14-year-olds

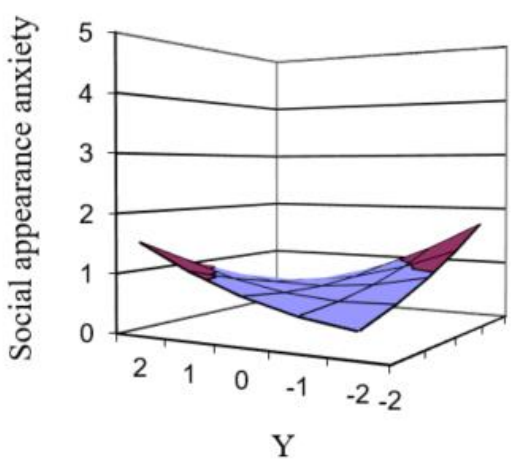

(centered perceived benefits scale)
$\mathrm{X}$

(centered

perceived costs perceived costs scale)

Figure 4. Results of the Response Surface Analysis for Social Appearance Anxiety as Predicted by Positive Outcome Expectancy - Negative Outcome Expectancy Discrepancy Across Three Age Groups (9- to 10-year-olds, 11-year-olds, and 12- to 14-year-olds, respectively). 


\section{Data Sharing Declaration}

The datasets generated and/or analyzed during the current study are not publicly available but are available from the corresponding author on reasonable request.

\section{Conflicts of Interest}

The authors report no conflict of interest.

\section{Compliance with Ethical Standards}

\section{Funding}

This research was funded by the FWO (Research Foundation Flanders) - Grant 12X0820N

\section{Ethical Approval}

The ethical committees of the host university approved the research project.

\section{Informed Consent}

Active consent was obtained from both the parents and adolescents before the respondents filled out the paper-and-pencil surveys. 